\title{
Simulation-Based Planning and Control of Transport Flows in Port Logistic Systems
}

\author{
Antonio Diogo Passos Lima, Frederico Werner de Mascarenhas, \\ and Enzo Morosini Frazzon \\ Graduate Program in Production Engineering, Technology Center, Federal University of Santa Catarina (UFSC), \\ University Campus, P.O. Box 476, Trindade, 88040-900 Florianópolis, SC, Brazil \\ Correspondence should be addressed to Enzo Morosini Frazzon; enzo.frazzon@ufsc.br
}

Received 4 April 2014; Accepted 26 June 2014

Academic Editor: Michael Freitag

Copyright (C) 2015 Antonio Diogo Passos Lima et al. This is an open access article distributed under the Creative Commons Attribution License, which permits unrestricted use, distribution, and reproduction in any medium, provided the original work is properly cited.

\begin{abstract}
In highly dynamic and uncertain transport conditions, transport transit time has to be continuously monitored so that the service level is ensured at a proper cost. The aim of this research is to propose and to test a procedure which allows an agile planning and control of transport flows in port logistic systems. The procedure couples an agent-based simulation and a queueing theory model. In this paper, the transport scheduling performed by an agent at the intermodal terminal was taken into consideration. The decision-making agent takes into account data which is acquired in remote points of the system. The obtained results indicate the relevance of continuously considering, for the transport planning and control, the expected transit time and further waiting times along port logistic systems.
\end{abstract}

\section{Introduction}

Disturbances of internal or external origin can impact the reliability of freight transport. In this case, unreliable transport service generates inefficiencies associated with not only an increase in costs but also a reduction in the service level. Among the disorders which can impact the stability of transport flows two stand out: traffic congestion due to the increasing traffic of vehicles and delays in the decision making process. Notwithstanding these occurrences which indicate capacity constraints, it is likely that the overall logistic infrastructure is still not used optimally in full.

Infrastructure issues of road access can impair the operational efficiency of the entire port sector, thus becoming an obstacle for social and economic national development [1]. According to Hijjar and Alexim [2], when port access is inefficient, the entire cargo transport operation is damaged because bottlenecks in the entrance of the port terminal can result in delays and extra need for storage, therefore, increasing the total logistic cost. To sum up, issues in port access directly affect the efficiency of terminals, exporting companies, and transportation costs. Chin and Tongzon [3] affirm that logistic infrastructure makes up a vital link in the overall chain of commerce, contributing to the international competition of a nation. Bittencourt [4] has stated that the logistic port model to send and receive cargo usually consists of port operators making time windows available, in which each shipper sends their vehicles into the port. However, once traffic conditions are uncertain and there is no access control to the port zone, shippers ultimately send in their vehicles at same time window, looking either for convenience or for guaranteeing goods delivery. Studies on new port logistic methods which enable rationalizing vehicle traffic and optimizing port cargo load meet the current need to improve road infrastructures, stimulating greater control and improvements in the national logistic scenario $[5,6]$.

Between two nodes in a logistics network, normally more than one possible route is available. In other words, more than one route choice linking the transport origin and destination may be chosen. In this case, the decision on which route should be used can reduce the impact caused by the large amount of traffic flow at a given time, mainly if the routing decision is taken quickly on the basis of the observation of changes in the environment. It is also pointed out that competitive markets require greater agility from transport operations so that they can respond quickly to fluctuations 
[7-9]. Nevertheless, currently, most transport schedules take into account only local restrictions, ignoring dynamic environmental variables or external disturbances [10].

An important review of recent mathematical programming models that deal with this subject was made by Mula et al. [11]. Apart from that, noteworthy real-time approaches are being studied in order to address requirements of highly dynamic systems. Among the programming techniques being studied, robust programming can be highlighted. This type of programming is aimed at creating intelligent predictive schedules that minimize the effects of disturbances on the performance of the implemented schedule. Among various existing robust programming techniques, genetic algorithms, multiple predefined schedules, and fuzzy stand out $[12,13]$.

The application of an agent-based simulation in the preparation of the transport schedule can be an effective solution to mitigate the aforementioned impacts of raising transport volumes. Taking into account the complexity of the involved structures and the set of factors to be considered, the development of a procedure to decide the route to be used by a transport vehicle so that it can be applied on port logistic chains is quite challenging, both in scientific and in practical terms. In this context, this paper proposes a procedure, based on the application of stochastic queueing models, to reduce the impacts caused by increased transport time due to traffic congestion on the route. The analysis of the performance of the proposed procedure employs a test case, implemented through a simulation model representing a port logistic chain that includes transport flows, an intermodal logistics terminal, and a port terminal.

\section{Literature Review}

Several transport flow optimization problems can be solved using exact methods, such as Assad [14], for instance, route displacement minimization and minimization of number of used routes. However, despite the capability of exact methods to find a solution, these techniques are not the most used for solving NP-hard problems, since the processing time increases with the complexity of mentioned problems [15]. Apart from exact methods, other techniques available for solving transport flow optimization problems can be classified as [16] heuristic and metaheuristic methods. In a study by Bonasser and Gualda [17], several techniques are presented.

When there is a problem that takes into account only the length of the route to be used by a vehicle, this problem can be classified as a vehicle routing problem (VRP). In Bonasser and Gualda [17], the following variants of the vehicle routing problem are presented: heterogeneous fleet and sizing and allocation of fleet (fleet size and mix VRP). Furthermore, this study shows subvariants of the heterogeneous fleet and also techniques used to solve each variant of the VRP. Otherwise, Raff [15] classifies routing problem into the following types: single depot, multiple-vehicle, node routing problem; multiple depot, multiple-vehicle, node routing problem; and single depot, multiple-vehicle, node routing problem with stochastic demand. Regarding the complexity of a routing problem, this is enhanced through the inclusion of the following constraints [15]: specification of a time period in which a vehicle must be in service before it returns to its point of origin; specification of tasks that can only be performed by certain types of resources; and specification of multiple garages where the vehicles may be stored. In addition to the concept of vehicle routing problems, it is necessary to differentiate it from the concept of scheduling problems. The last is mainly characterized by the routing mechanism of each vehicle that is established in the transport schedule and only takes into account time and space.

Concerning the existing queueing models, depending on the perspective utilized, those can receive different classifications. Thus, from the user point of view, the existing queues are classified as follows [18]: generative models-they provide the user with an optimal solution that satisfies the objective function; and evaluative models-although they do not provide an optimal solution that satisfies the user objective function, those models help in the evaluation of a set of decisions by providing performance metrics. Queueing networks models are classified as evaluative methods. Besides this form of classification, it is possible to classify queueing methods by the accuracy of obtained results [18]: (i) models that provide exact results - these models are difficult to obtain and only available for queueing network models of small size; (ii) models that provide approximate results. So, in this type of model, there is a tradeoff between complexity and accuracy. Still, if one wishes to efficiently analyse a network queue model with finite overall processing time, this approach is the most appropriate [18]. Other recent studies involving queuing models are described in Abdelkader and Al-Wohaibi [19] and Dragović et al. [20]. The first study proposed a new performance measure in a single server Markovian queuing system. The second one refers to a model that combines finite waiting areas, batch arrival queues, and identical and independent cargo-handling capacities.

The following dispatching methods were listed in a study by $\mathrm{Wu}$ and Chen [21]: dispatching rules; heuristics; data mining based approaches; agent technologies; and simulation. Moreover, the aforementioned work demonstrated that several studies have been conducted in an attempt to solve the problem of scheduling. Regarding the approaches used in these studies, $\mathrm{Wu}$ and Chen [21] highlight the following: (i) selection of the most appropriate dispatching rule among those that are available; (ii) inclusion of adjustable parameters that can optimize the dispatching rule; and (iii) best estimate of the schedule through the results of a limited number of simulations. As for the approach (ii), it is emphasized that this can only be used with factors that are defined previously and remain static [21]. Regarding dispatching rules, these can be considered a practical method for scheduling [22]. Different classifications of dispatching rules can be described [23]: static - the priority of waiting jobs does not change over time; dynamic - the priority of waiting jobs changes over time; local-decisions are taken only from the jobs that are waiting for service; and global-decisions are made with the use of additional information about jobs or other workstations machines.

In a study by Panwalker and Iskander [23], the ordering rules and their respective characteristics were also presented. 


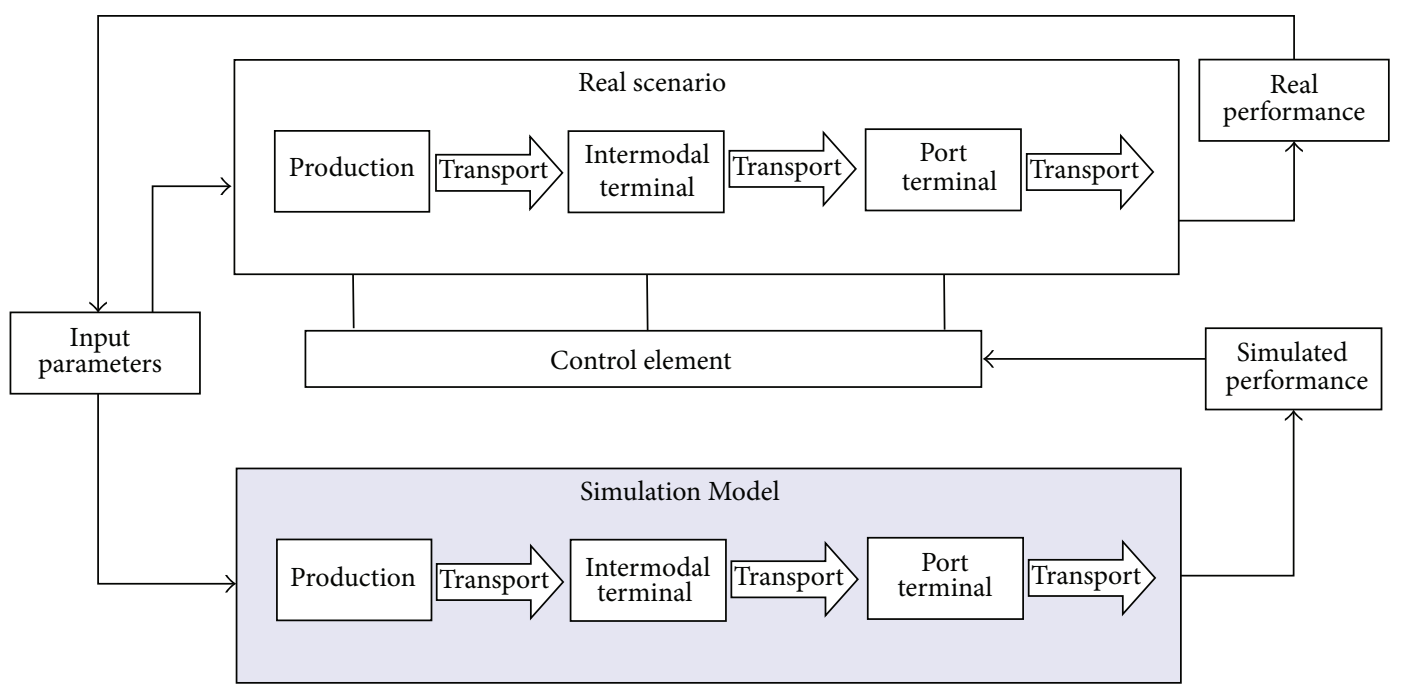

FIGURE 1: Approach to a simulation-based planning and control of port logistic system.

The rules listed in this study are classified as below: simple rules priority-based on information related to a single job; combination of simple rules of priority-two simple priority pieces of information are used when defining the priority; weighted priority rules-similar to the above classification, but with the use of weights; heuristic scheduling rules; and other rules, such as the use of specific rules for particular production sets. In the study of Azimi et al. [24], different kinds of dispatching rules were detailed. Although this study focused on a multiple-load AGV System, the concepts related to dispatching rules also apply to the transport scheduling problem. The study also differentiated categories of the route selection problem regarding the presence of stochastic events.

Due to the increasing complexity of transport flow problems as it integrates a larger number of elements in the model and the increase in the computing power, the use of simulation to solve this kind of problem has become an attractive option. In this case, simulations are usually employed when [25] a model presents variables that are not deterministic and when the problem requires both time and space integration. Models are the translation of operational requirements and constraints to the understanding of the process by the computer [26]. The representation quality of a model regarding the analysed logistics process influences directly the results provided by the model. Once the model of a logistics process is complete, the simulation is typically applied to one of the following purposes [25]: as a tool for identifying and evaluating the improvement of the operating performance or as a tool to gain a better understanding of the costs and performance potential of logistics operations. In this sense, customized simulations can be used to support reengineering decisions [27]. According to Swaminathan et al. [27], simulation is the only viable platform for detailed analysis of alternative solutions because the complex interactions between the entities of a supply chain do not allow the use of analytical solutions. Furthermore, nonprescriptive insights generated from qualitative analyzes, such as benchmarking, do not allow other conclusions that are not related to the current trends. Swaminathan et al. [27] also point out that the major problems of simulation are associated with the time and effort required to develop specific models with sufficient fidelity to the actual supply chain of interest and the limited reuse of the simulation models.

\section{Simulation-Based Planning and Control of Transport Flows}

The approach is embedded in a procedure, which is based on the application of stochastic queueing models for improving dispatching rules and synchronizing transport flows in port logistic systems. The aim of this research is to propose and to test a procedure which allows for an agile planning and control of port logistics. The procedure couples an agent-based simulation and a queueing theory model. From the literature review, the proposed procedure considers the following:

(i) maximization of the quantity of goods delivered as the objective function;

(ii) a solution of the following vehicle routing problem: single depot, multiple-vehicle, and node routing problem; moreover, the problem addressed in this proposal presents a high degree of complexity, because it is constrained by a time window in which a vehicle must be in service before it returns to its point of origin [15];

(iii) use of queueing theory models as evaluative models as well as to provide approximate results [18];

(iv) use of dispatching rules which are classified as static at the bottleneck and global at the intermodal terminal [23];

(v) use of simulation as a tool to identify and evaluate the performance improvement operations [25].

The conceptual view which motivated the proposed approach for the simulation-based planning and control of port logistic systems is presented in Figure 1. For a generic 


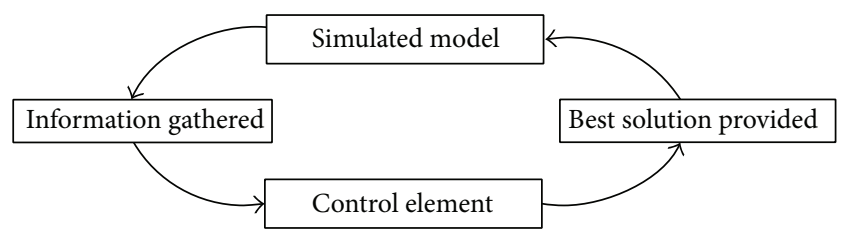

Figure 2: Approach to stages 2 and 3 of the simulation-based planning and control of transport flows.

export logistics chain, the concept embraces the following stages: (1) a representation of the real scenario, occurring in real time, subject to the input parameters and generating the output data (real performance) at each time interval; (2) a simulation model, subject to the input parameters and generating the output data (simulated performance), running in simulated time, to be executed numerous times, so that the results can be evaluated by an external control element; (3) a control element that evaluates the obtained simulated performance and, according to a predetermined control logic, allows for the effective implementation in the real scenario.

The research conducted in this paper comprises stages 2 (simulation model) and 3 (control element) for a simplified port logistic chain embracing an intermodal terminal, a transport operation, and the arrival at a port terminal, as represented in Figure 2.

As for the control element, this part has been accomplished through the use of predefined parameters. Thus, with the exception of the number of customers waiting for service on the bottleneck, the control assumed that all other parameter settings of the model remained constant. This case will be performed using a model that includes a scenario of an export logistics chain in which the cargo of an intermodal terminal should be dispatched at the lowest possible cost to a port terminal.

The simulation model represents the actual operation of a port logistic system comprising an intermodal terminal, a transport operation, and the arrival at a port terminal. Figure 3 illustrates the structure of the model.

The decision to dispatch the cargo is carried out early in the day and involves only the choice of the route to be held by transport vehicles. Besides that, the dispatching decisions vary in accordance to the following factors: quantity of goods in inventories of the intermodal terminal; traffic congestion of each road; and end time scheduled for the carriage of goods by the transport vehicle.

Furthermore, in an effort to address the above problem as a nondeterministic, this problem will not only have random components but also display queuing along the routes due to the low carrying capacity compared with the traffic demand. With this purpose, this study will evaluate the impact of the transport scheduling when the responsible agent takes decisions based on the information provided by a control element. The control can monitor the traffic on the routes that can be used by transport vehicles. The information that will be used as input to the control is the quantity of goods that are in the intermodal terminal; the estimated transport transit time on the routes due to the presence of traffic congestion; and the amount of time remaining for the cargo transportation by
TABLE 1: Notation of transport transit time components.

\begin{tabular}{ll}
\hline Constant parameters & \\
\hline$T_{R}$ & $\begin{array}{l}\text { Travel time required to return the vehicle } \\
\text { to the intermodal terminal from the port } \\
\text { (hours) } \\
T_{L}\end{array}$ \\
$T_{U}$ & $\begin{array}{l}\text { Time to load the cargo at the vehicle } \\
\text { (hours) } \\
\text { Time to unload the cargo at the vehicle } \\
\text { (hours) }\end{array}$ \\
\hline$T_{V T}$ & Travel time to the port terminal (hours) \\
$T_{P}$ & Processing time at the bottleneck (hours)
\end{tabular}

the available transport vehicles. To calculate the transport transit time, the following equation will be used:

$$
T_{T}=\left(T_{P}+T_{V T}+T_{L}+T_{U}+T_{R}\right) .
$$

Table 1 presents the description of the parameters of the above formula.

In an effort to calculate the estimated processing time $\left(T_{P}\right)$ of the vehicles at the bottlenecks of the routes where traffic congestion occurs, the problem was modelled as the type M/M/C: ( $\infty$, FIFO). In this modelling, $C$ is the number of tracks of a given route. Thus, to support the transportation schedule of the day, the estimated transport transit time $\left(T_{T}\right)$ on the routes was calculated from an estimate of the average waiting time of the vehicles in the system when a certain amount of vehicles in the queue was observed. For instance, this information could be obtained by monitoring cameras at the critical bottleneck of each route (Figure 3).

With the purpose of clarifying the understanding of the procedure used to calculate the estimated processing time $\left(T_{P}\right)$ of the vehicles at the bottlenecks, the steps used by the control element are described below:

(1) data-collection regarding the amount of vehicles at the bottleneck of each route;

(2) the control element's identification of the class that includes, in its amplitude, the information collected in step 1, through the use of a table previously generated;

(3) association of the situation observed in step 1 to a queue problem which presents a service rate $(\mu)$ previously raised and an arrival rate $(\lambda)$ corresponding to the class identified in step 2;

(4) utilization of the average waiting time $(W)$ from the queue problem associated in step 3 as the estimative of the processing time $\left(T_{P}\right)$ of the vehicles at the bottleneck.

Regarding the table used in step 2 of the aforementioned procedure, it was created using a computational algorithm. In this case, a range of data was defined for each bottleneck that would be used for the control decision. After that, this range of data was divided into 4 classes of equal amplitude. Using 4 classes of equal amplitude allows for the construction of the simulation model. It is important to remark that the use of 


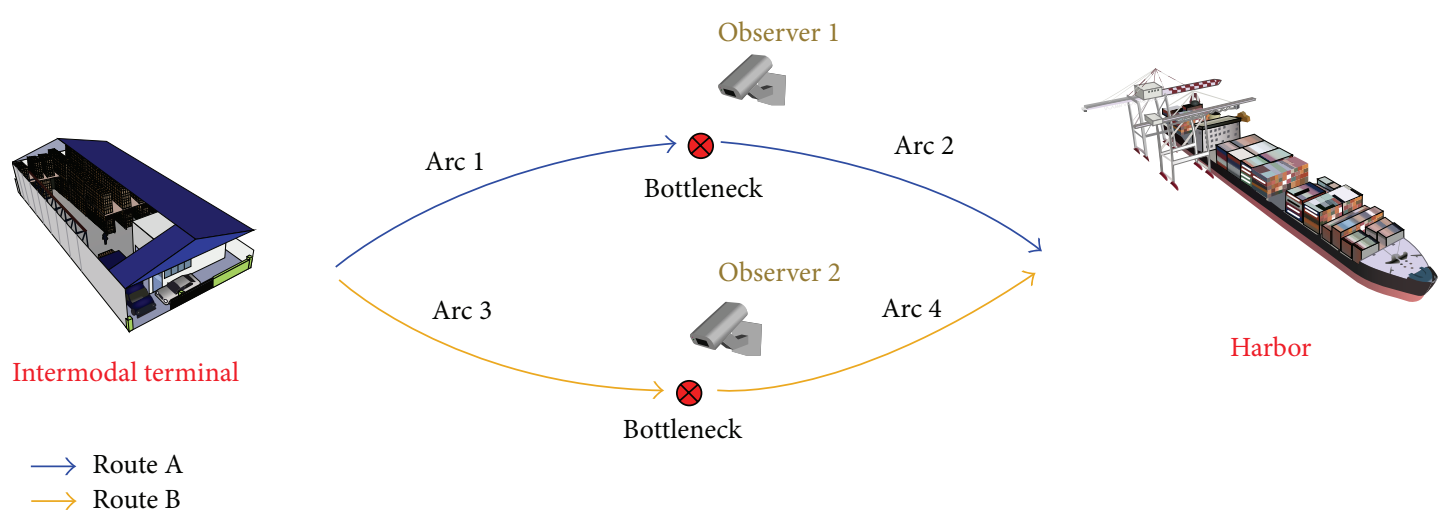

FIGURE 3: Model structure.

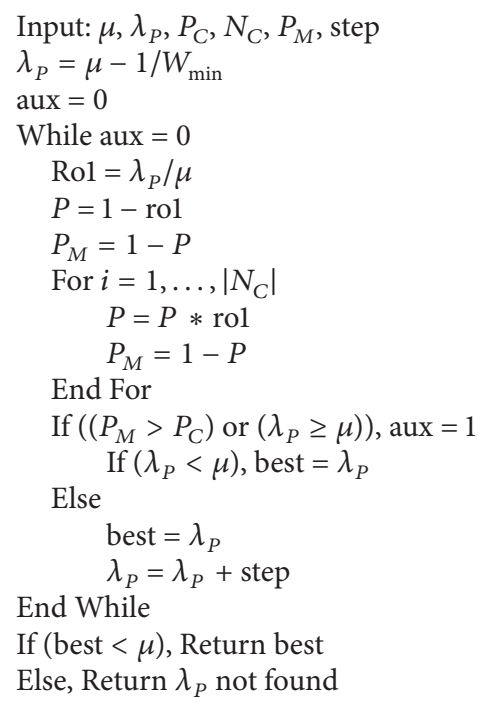

If (best $<\mu$ ), Return best

Else, Return $\lambda_{P}$ not found

Algorithm 1

a greater amount of data classes increases the sensitivity of the control element.

In the sequence, for each class, several iterations were performed, in order to identify the queue model that possesses the following characteristics: service rate $(\mu)$ corresponding to the bottleneck in analysis and probability of finding a number of customers at the top of the central element of the class greater than $50 \%$. After that, the information concerning the arrival rate $(\lambda)$ and average waiting time $(W)$ of the identified queue model was recorded in the respective classes. This computational algorithm is presented in Algorithm 1.

Algorithm 1 starts with the following input data:

(i) service rate of the modelled bottleneck $(\mu)$,

(ii) lowest average waiting time in the system $\left(W_{\min }\right)$;

(iii) thenumber of customers that, above this, has a probability of occurrence greater than $P_{C}\left(N_{C}\right)$;

(iv) minimum probability of finding more than $N_{C}$ clients $\left(P_{C}\right)$;

(v) step size used by the algorithm to find the arrival rate (step).
Algorithm 1 calculates the initial value of the arrival rate of customers in the queue $\left(\lambda_{P}\right)$ that will later be incremented, throughout the execution of the algorithm. In doing so, while the probability of occurrence of more than $N_{C}$ customers in the queue is less than $P_{C}$, the value of the variable $\lambda_{P}$ will be increased by the step value. However, if the value of $\lambda_{P}$ becomes greater than or equal to $\mu$, the value of the variable $\lambda_{P}$ will no longer receive any increment. This way, in order to make $\lambda_{P}$ receive the least amount of increment, a variable of control (aux) was included in the algorithm. Thus, while this control variable remains at zero, the algorithm through the while loop calculates the probability of finding more than one customer in the queue when it presents an arrival rate $\lambda_{P}$ and a service rate $\mu$. The result of this calculation is stored in the variable $P_{M}$. Next, the algorithm uses the For loop to calculate the probability of finding more than $N_{C}$ customers in the queue. This calculation involves an update on the value of the variable $P_{M}$.

At the end of the For loop, the algorithm makes a comparison of the value of $P_{M}$ found with the value of $P_{C}$, as well as the value of $\lambda_{P}$ with the value of the service rate of the modeled bottleneck $(\mu)$. In this case, the control variable aux is updated with the value 1 if it satisfies one of the following conditions: the value of the probability of finding more than $N_{C}$ customers in the queue $\left(P_{M}\right)$ is greater than $P_{C}$ and the $\lambda_{P}$ is greater than or equal to $\mu$, in which the algorithm cannot determine an arrival rate that meets the input requirements without a modification on the value of $\mu$ or step. Furthermore, if the value of $P_{M}$ is greater than the value of $P_{C}$ and $\lambda_{P}$ is less than $\mu$, the algorithm stores the value of the variable $\lambda_{P}$ on the variable best. If the required conditions to an update of the variable aux to 1 were not met, the algorithm stores the value of the variable $\lambda_{P}$ on the variable best and increments the $\lambda_{P}$ value in a step value. At the end of the While loop, the algorithm returns the value of $\lambda_{P}$ found in the last iteration of this loop if that variable was lower than $\mu$. Otherwise, the algorithm reports that it failed to find a $\lambda_{P}$ that meets the entry restrictions.

Finally, the goal is to evaluate transport scheduling performed by an intermodal terminal agent seeking the lowest transport cost. Therefore, agent's objective function is 
TABLE 2: Notation of the objective function.

\begin{tabular}{|c|c|}
\hline \multicolumn{2}{|l|}{ Index } \\
\hline$W$ & Days $(1, \ldots, 10)$ \\
\hline \multicolumn{2}{|c|}{ Constant parameters } \\
\hline$c_{I}$ & Storage cost in the intermodal (mu/hour) \\
\hline $\mathrm{ct}_{D}$ & Cost of the transportation (mu/hour) \\
\hline $\mathrm{ct}_{N}$ & $\begin{array}{l}\text { Additional cost of transportation added } \\
\text { after } 9 \text { p.m. at the cost of the } \\
\text { transportation (mu/hours) }\end{array}$ \\
\hline$c_{F}$ & Cost of not transported goods \\
\hline \multicolumn{2}{|c|}{ Variables } \\
\hline$t_{I}$ & $\begin{array}{l}\text { Total time in which the products were at } \\
\text { intermodal (hours) }\end{array}$ \\
\hline$t_{D}$ & $\begin{array}{l}\text { Total time in which the products were in } \\
\text { transit (hours) }\end{array}$ \\
\hline$t_{N}$ & $\begin{array}{l}\text { Total travel time of vehicles that were still } \\
\text { in use after } 9 \text { p.m. (hours) }\end{array}$ \\
\hline Q & $\begin{array}{l}\text { Quantity of goods that were not } \\
\text { transported }\end{array}$ \\
\hline
\end{tabular}

the minimization of all costs perceived by that agent. The respective cost formula is presented in

$$
\begin{gathered}
\min Z=\sum_{w=1}^{10}\left(c_{I} * t_{w I}+\mathrm{ct}_{N} * t_{w N}+\mathrm{ct}_{D}\right. \\
\left.* t_{w D}+c_{F} * Q\right) .
\end{gathered}
$$

Table 2 presents parameters description.

The objective function will be used in the analysis of each simulation scenario, enabling the performance assessment of the proposed procedure. It is noteworthy that the decision of the control element will be based on estimates of the traffic arrival rate $(\lambda)$ at the bottleneck. Moreover, as this decision is made based on information gathered by an observer who is far from the decision maker, differences are expected between the results obtained and those predicted processing time at the bottleneck.

The computational algorithm used by the control element is presented in Algorithm 2. Algorithm 2 receives as input the results obtained by the use of Formula 1 for each one of the routes to the port. Thus, Algorithm 2 starts with the following input data:

(i) expected transport transit time for route $\mathrm{A}$;

(ii) expected transport transit time for route $\mathrm{B}$.

Algorithm 2 checks which route has the lowest transport transit time $\left(T_{T}\right)$. This verification by the control element is required every time a transport vehicle is available at the intermodal terminal and cargo needs to be transported to the port terminal. In the sequence, the algorithm checks if the transport of the goods can be performed before 9 p.m. (21:00 h). If possible, the transportation will be assigned to the vehicle. Otherwise, there will be no more transport assigned for that vehicle on that day. Besides that, once a cargo transport is assigned to a vehicle, it will be carried out.

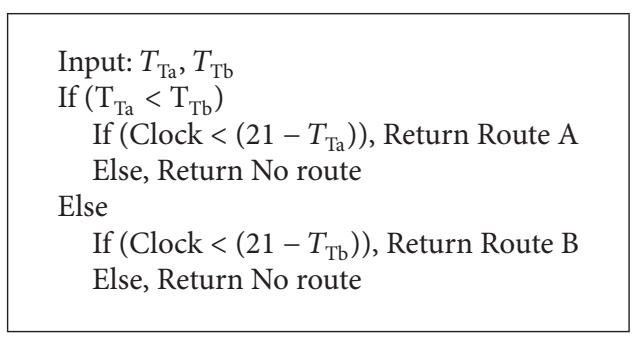

Algorithm 2

The control element makes its decisions based on an expectation of transport transit time $\left(T_{T}\right)$ due to the uncertainty regarding the processing time $\left(P_{T}\right)$ at the bottleneck. The $P_{T}$ used is based on an estimate of the average waiting time $(W)$ if this problem was modelled as a queue of type M/M/C: ( $\infty$, FIFO). Still, since the decisions of the control element are based on expectation that may change by the time the transport vehicle reaches the bottleneck, it is possible that some transportation vehicles continue in operation after 9 p.m. In this case, it is noteworthy that while the $W$ used by the control element depends on the traffic observed in the bottleneck when the transport vehicle is still in the intermodal terminal, the ideal $W$ depends on the arrival rate $(\lambda)$ in the bottleneck when the transport vehicle reaches it.

\section{Test Case of Port Logistic Systems}

This research comprised the modelling of agents involved in the chain through the use of process modelling techniques. After that, the impact of decisions of an agent in the rest of the chain was analysed, using a simulation model. The simulation model was implemented using Simio LLC software [28]. Initially, the model was calibrated so that, depending on the traffic flow, a queue could be formed in any of the routes used to transport the cargo from the intermodal terminal to the port terminal. Moreover, an additional calibration was performed in the traffic flow to eliminate the possibility of a modelled route becoming predominantly better than others due only to their travel time $\left(T_{V T}\right)$. In addition, the following operational constraints were established in the model: the transport vehicle should return to its place of departure before the end of the day; the carrying capacity of each vehicle is limited to only 1 unit; refusal of transport services occurs if the total journey is set to finish after 9 p.m.; and an additional cost is set when the transport vehicle cannot finish its journey before 9 p.m. due to the elapsed time in the queue.

Figure 4 illustrates the simulation model that was implemented in Simio LLC to evaluate the impact of decisions of an agent in the rest of the export logistics chain.

Concerning the modelling, not only of the delivery of goods to the port but also of the end of the traffic congestion after the bottleneck of each route, two sinks were included at the end of the routes: one traffic sink and one port sink. While the traffic sink absorbs all vehicles originating traffic on each route, the port sink absorbs all goods shipped at the intermodal terminal. 


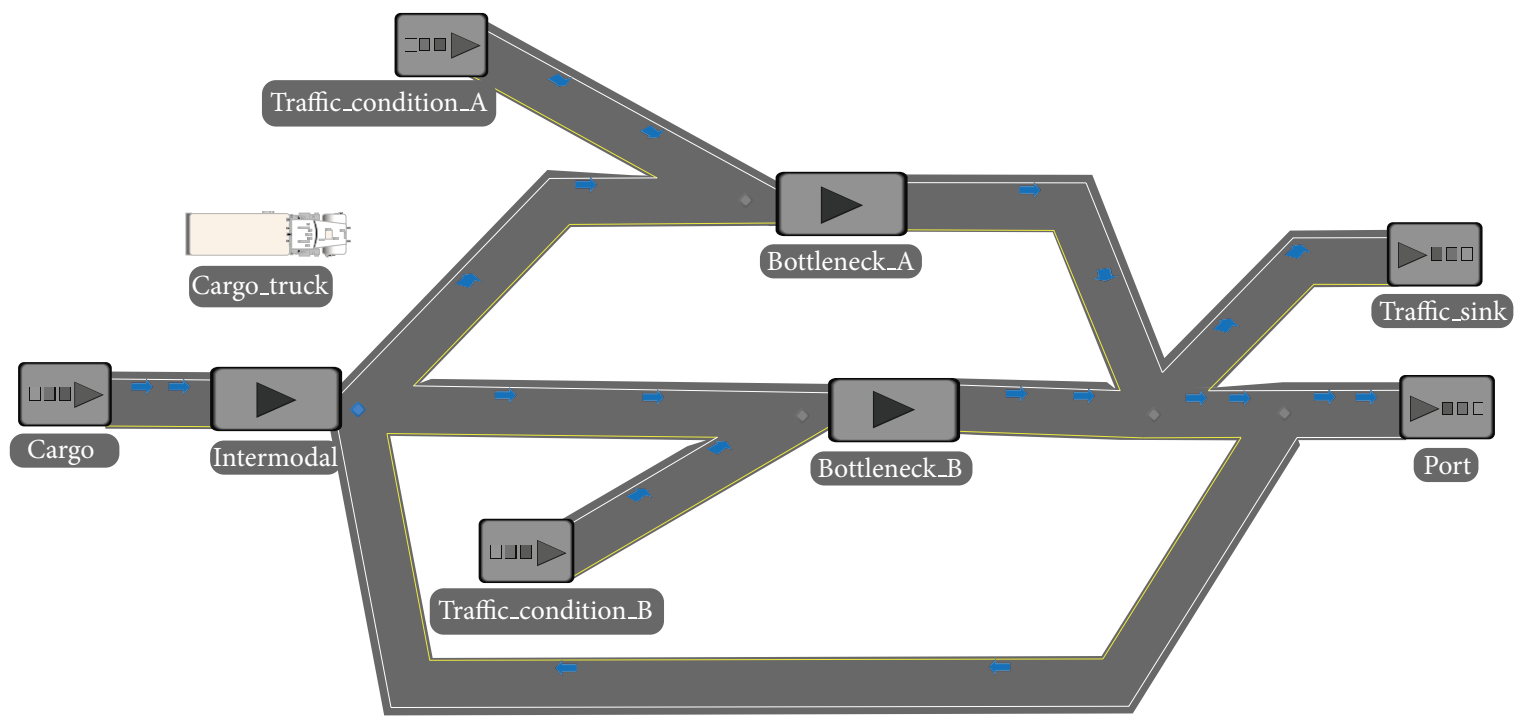

FIGURE 4: Simulation model implemented in Simio LLC.

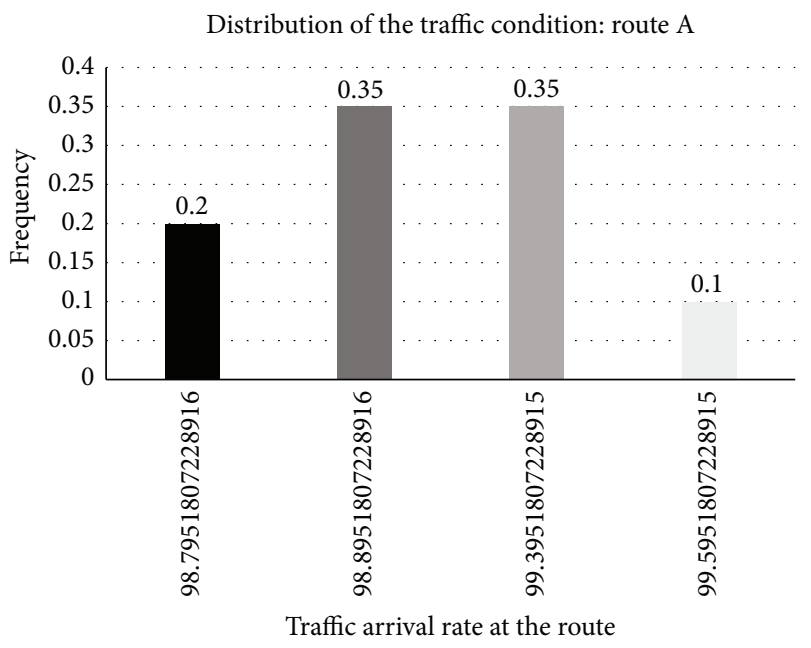

Figure 5: Frequency distribution of the traffic arrival rate $(\lambda)$ at route $\mathrm{A}$.

In order to enable the comparison of results, the amount of products available to be shipped at the intermodal terminal inventories will be set to the value of 9 units at the beginning of each day. Besides that, 3 vehicles were also used, each one with the capacity to transport one cargo at a time.

With regard to the traffic congestion representation in the model, this was accomplished with the inclusion of other vehicles in each of the routes used by the cargo transportation. In this case, the arrival rate of these vehicles at the bottlenecks of each route can assume values varying in accordance to a frequency distribution. Figures 5 and 6 present, respectively, the frequency distribution of the possible values of the traffic arrival rate $(\lambda)$ that were used to induce traffic congestion at routes $\mathrm{A}$ and $\mathrm{B}$.

The values regarding the traffic arrival rate $(\lambda)$ at the bottleneck were used in order to allow the processing time

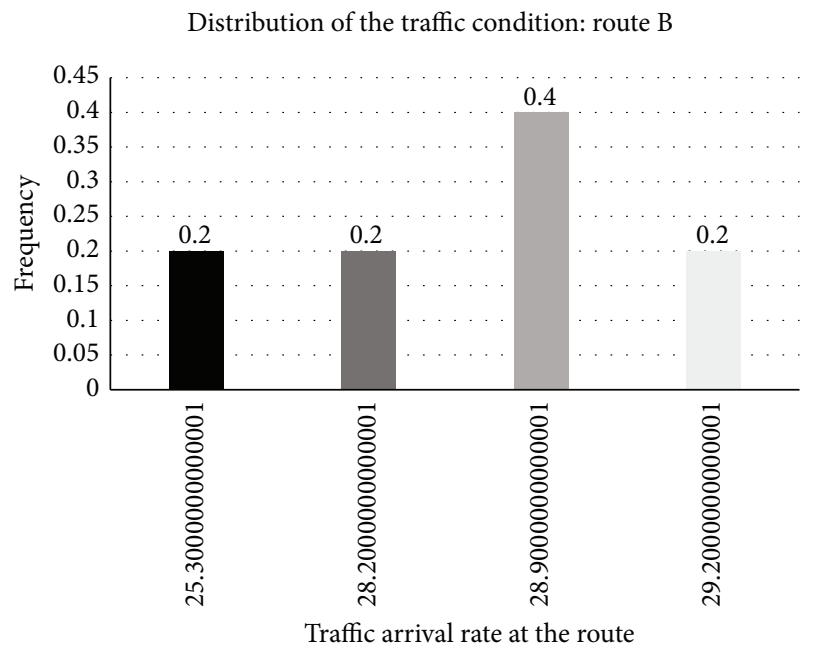

FIGURE 6: Frequency distribution of the traffic arrival rate $(\lambda)$ at route $\mathrm{B}$.

$\left(P_{T}\right)$ of the vehicle on the bottleneck to match the average waiting time $(W)$ calculated numerically.

The decisions to be taken by the control element will be performed with the use not only of information regarding the number of vehicles at the bottlenecks of each route but also of information stored in its database. Tables 3 and 4 show, respectively, the information stored in the control element database that is used to assess the situation observed at the bottlenecks of routes $\mathrm{A}$ and $\mathrm{B}$.

Regarding the values presented at the column "average waiting time" of Tables 3 and 4, they were previously calculated. These values were obtained not only by modelling the bottleneck problem as a queue of type M/M/1: ( $\infty$, FIFO) but also by considering knowledge of the arrival rate and service rate. It is pointed out that the control element decides which route should be used without being certain about the amount 
TABLE 3: Control element database used to evaluate the traffic conditions of route A.

\begin{tabular}{|c|c|c|c|c|}
\hline & & Route A & & \\
\hline $\begin{array}{l}\text { Lower limit of } \\
\text { customers }\end{array}$ & $\begin{array}{l}\text { Upper limit of } \\
\text { customers }\end{array}$ & $\begin{array}{c}\text { Number of customers } \\
\text { whose probability of } \\
\text { finding this amount in } \\
\text { the queue is greater than } \\
50 \%\end{array}$ & $\begin{array}{l}\text { Number of vehicles } \\
\text { per hour }(\lambda)\end{array}$ & $\begin{array}{l}\text { Average waiting time in } \\
\text { the system in hours }(W)\end{array}$ \\
\hline 0 & 79 & 40 & 98,7951807228916 & 0,8300 \\
\hline 80 & 159 & 120 & 98,8951807228916 & 1,9809 \\
\hline 160 & 239 & 200 & 99,3951807228915 & 3,2806 \\
\hline 240 & 319 & 280 & 99,5951807228915 & 4,8824 \\
\hline
\end{tabular}

TABLE 4: Control element database used to evaluate the traffic conditions of route B.

\begin{tabular}{lcccc}
\hline $\begin{array}{l}\text { Lower limit of } \\
\text { customers }\end{array}$ & $\begin{array}{c}\text { Upper limit of } \\
\text { customers }\end{array}$ & $\begin{array}{c}\text { Number of customers } \\
\text { whose probability of } \\
\text { finding this amount in the } \\
\text { queue is greater than } 50 \%\end{array}$ & $\begin{array}{c}\text { Number of vehicles } \\
\text { per hour }(\lambda)\end{array}$ & $\begin{array}{c}\text { Average waiting time in } \\
\text { the system in hours }(W)\end{array}$ \\
\hline 0 & 6 & 3 & 25,3000000000001 & 0,2128 \\
7 & 13 & 10 & 28,2000000000001 & 0,5556 \\
14 & 20 & 17 & 28,9000000000001 & 0,9091 \\
21 & 27 & 24 & 29,2000000000001 & 1,2500 \\
\hline
\end{tabular}

of vehicles which will be waiting at the time the transport vehicle reaches the bottleneck.

This uncertainty arises from the following reasons: (i) there is a time difference between the time when the control element takes its decision and the time when the transport vehicle arrives at the bottleneck, since this decision occurs when the vehicle is still in the intermodal terminal and (ii) the traffic arrival rate $(\lambda)$ of each route follows an exponential distribution.

Given the above reasons, the decision on the route that should be used is based on an estimation about the number of vehicles per hour $(\lambda)$ on each route. Furthermore, in order to create a comparison among the proposed scenarios, the corresponding values of the variables that follow a frequency distribution were selected from random numbers. Table 5 illustrates the values that were randomly selected for these variables in each day contemplated in the simulation period. In this table, the random values obtained for the selection of the traffic arrival rate of routes A and B are shown in columns "A.N. flow of vehicles," where A.N. means aleatory number.

Regarding the return of the vehicle to the intermodal terminal, it was assumed that the vehicle would perform this route without any delay caused by traffic. Furthermore, as a consequence of modelling traffic arrival rate $(\lambda)$ at the bottlenecks as an exponential distribution, the model needed to be run 100 times, for each day, so that the stochastic results converged. As for the other parameters required for the implementation of the model, their values did not vary in the days contemplated in the simulation period. The values of these parameters are shown in Table 6.

Concerning the cost factors of the proposed model, it is pointed out that the costs relating to $\mathrm{ct}_{D}$ and $\mathrm{ct}_{N}$ are associated with variables $a_{1}, a_{2}, a_{3}, a_{4}$, and $a_{5}$. In reference to the costs related to the unloading cargo at the port terminal, they are considered to be zero in this model.

\section{Results and Discussion}

In addition to the simulation model developed in Simio LLC for the impact analysis of the transport scheduling performed by an agent using the proposed procedure, comparisons of the results for the following scenarios were conducted.

(i) 1st Scenario: transport schedule considers that all transport is carried out through the arch which presents a shorter route, but high traffic.

(ii) 2nd Scenario: transport schedule considers that all transport is carried out through the arch which presents a longer route, but low traffic.

(iii) 3rd Scenario: transport schedule is adjusted throughout the day according to an expectation of the time spent by the available vehicles to perform a given transportation.

5.1. 1st Scenario: Transport Schedule-All Vehicles Use Route $A$. In this scenario, the transport schedule is performed such that all transport to the port is made at route A (route that has the shortest path but high traffic). Moreover, the transport schedule did not take into account an evaluation of the expected transport transit time, in other words, did not evaluate the processing time at the bottleneck. Thus, the information taken into account in the transport schedule is referring to (i) number of vehicles available; (ii) amount of each type of product to be transported; (iii) the remainder of 
TABLE 5: Selected values for each random variable comprised in the period of simulation.

\begin{tabular}{lcccc}
\hline Days & $\begin{array}{c}\text { A.N. flow of vehicles: } \\
\text { route A }\end{array}$ & $\begin{array}{c}\text { Traffic arrival rate }(\lambda) \text { at } \\
\text { route A } \\
\text { (no. of vehicles/hour) }\end{array}$ & $\begin{array}{c}\text { A.N. flow of vehicles: } \\
\text { route B }\end{array}$ & $\begin{array}{c}\text { Traffic arrival rate }(\lambda) \text { at } \\
\text { route B } \\
\text { (no. of vehicles/hour) }\end{array}$ \\
\hline 1 & 0,72 & 99,3951807228915 & 0,56 & 28,9000000000001 \\
2 & 0,94 & 99,5951807228915 & 0,33 & 28,2000000000001 \\
3 & 0,91 & 99,5951807228915 & 0,69 & 28,9000000000001 \\
4 & 0,25 & 98,8951807228916 & 0,79 & 28,9000000000001 \\
5 & 0,1 & 98,7951807228916 & 0,31 & 28,2000000000001 \\
6 & 0,66 & 99,3951807228915 & 0,93 & 29,2000000000001 \\
7 & 0,59 & 99,3951807228915 & 0,07 & 25,3000000000001 \\
8 & 0,53 & 98,8951807228916 & 0,94 & 29,2000000000001 \\
9 & 0,58 & 99,3951807228915 & 0,42 & 28,9000000000001 \\
10 & 0,94 & 99,5951807228915 & 0,96 & 29,2000000000001 \\
\hline
\end{tabular}

TABLE 6: Value of the constant parameters.

\begin{tabular}{|c|c|c|}
\hline Parameter & Value & Description \\
\hline$a_{1}$ & 0,9167 & Travel time of arc 1 from route A (hours) \\
\hline$a_{2}$ & 0,9167 & Travel time of arc 2 from route A (hours) \\
\hline$a_{3}$ & 1,25 & Travel time of arc 3 from route B (hours) \\
\hline$a_{4}$ & 1,25 & Travel time of arc 4 from route B (hours) \\
\hline$a_{5}$ & 1,833 & $\begin{array}{l}\text { Travel time of the vehicle return path } \\
\text { (hours) }\end{array}$ \\
\hline$c_{I}$ & 1,875 & Storage cost in the intermodal (mu/hour) \\
\hline $\mathrm{ct}_{D}$ & 11,25 & Cost of the transportation (mu/hour) \\
\hline $\mathrm{ct}_{N}$ & 16,25 & $\begin{array}{l}\text { Additional cost of transportation added } \\
\text { after } 9 \text { p.m. at the cost of the } \\
\text { transportation (mu/hour) }\end{array}$ \\
\hline$c_{F}$ & 250,00 & Cost of goods that were not transported \\
\hline$\mu_{a}$ & 100 & $\begin{array}{l}\text { Service rate (no. of vehicles/hour) of the } \\
\text { bottleneck of the route A }\end{array}$ \\
\hline$\mu_{b}$ & 30 & $\begin{array}{l}\text { Service rate (no. of vehicles/hour) of the } \\
\text { bottleneck of the route B }\end{array}$ \\
\hline$\Lambda_{A}$ & 3 & $\begin{array}{l}\text { Loading/unloading time of transport } \\
\text { vehicles (minutes) }\end{array}$ \\
\hline
\end{tabular}

the transport vehicle; and (iv) time needed for the transport vehicle which can carry out the collection and delivery of the product. Furthermore, in every day of the simulation period, the amount of goods available in the intermodal terminal, 9 in total, can be sent to the port by 3 vehicles at the time. Therefore, from this consideration and also from the considerations above, the transportation schedule for this scenario presents no difficulties. Using the above transportation schedule as input to the simulation model implemented in Simio LLC, the results were obtained in Table 7.

\subsection{2nd Scenario: Transport Schedule-All Vehicles Use Route}

$B$. Similar to the 1st simulation described, a new simulation was implemented, but the transport was performed only through route $\mathrm{B}$ (route that has the longest route, but little traffic) during the transport of goods from the intermodal terminal to the port terminal. Using the above transport schedule as input to the simulation model implemented in Simio LLC, the results were obtained in Table 8.

\subsection{3rd Scenario: Transport Schedule-Adjusted throughout} the Day according to an Expectation of the Time Spent by the Available Vehicles to Perform a Given Transportation. In this scenario, a change was made in the process that generates the transport schedule. At other scenarios, the transport schedule was used as input to the simulation model in Simio LLC. However, in this scenario, the transportation schedule was also generated at Simio LLC.

The transport schedule at this scenario was generated, during the simulation, while the need for transport and the vehicle availability were presented. Besides that, this transportation schedule did also take into account the traffic conditions that were observed at each bottleneck.

Furthermore, a restriction in the model was included so that only freights with the expected completion time before 9 p.m. were scheduled. Thus, during the simulation period of 10 days, in the simulation model implemented in Simio LLC, the results were obtained in Table 9.

5.4. Analysis. It was observed, in all scenarios, that transport was performed after 9 p.m. In spite of that, it was also possible to visualise different costs for each scenario. In the 1st Scenario, due to shorter travel time in the days when the traffic at route $A$ was not intense, the transport transit time on this route became significantly lower when compared to the transport transit time on route $\mathrm{B}$. Regarding the amount of goods that were not transported and the total travel time after 9 p.m., this scenario presented the worst results, due to those days of high traffic at route A. Concerning the sum of average costs after simulation replications of this scenario, it displays the highest values when compared to other scenarios.

In the 2nd Scenario, the dispatch of all goods was carried with the use of route $B$. In this case, with the exception of the total time in which the products were in transit, all other cost factors were lower when compared to the results of the 1st Scenario. Thus, despite the fact that the travel time of route $\mathrm{B}$ is longer than the respective time of route $\mathrm{A}$, it is pointed 
TABLE 7: Results when all transports are made with the use of route A.

\begin{tabular}{|c|c|c|c|c|c|c|}
\hline \multicolumn{6}{|c|}{ Average results from 1st Scenario after simulation replications } & \multirow{2}{*}{$\begin{array}{l}\text { Sum of average } \\
\text { Costs after } \\
\text { simulation } \\
\text { replications }\end{array}$} \\
\hline & $\begin{array}{l}\text { Total time in which } \\
\text { the products were } \\
\text { in transit (h) }\end{array}$ & $\begin{array}{l}\text { Number of vehicles } \\
\text { in use after } 9 \text { p.m. }\end{array}$ & $\begin{array}{l}\text { Total travel time } \\
\text { after } 9 \text { p.m. }\end{array}$ & $\begin{array}{l}\text { Total time in which } \\
\text { the products were } \\
\text { found stored }(\mathrm{h})\end{array}$ & $\begin{array}{c}\text { Amount of } \\
\text { products that were } \\
\text { not transported }\end{array}$ & \\
\hline $\begin{array}{l}\text { Average results } \\
\text { after simulation } \\
\text { replications }\end{array}$ & 295,74 & 17 & 88,25 & 515,17 & 5,87 & - \\
\hline $\begin{array}{l}\text { Average costs after } \\
\text { simulation } \\
\text { replications }\end{array}$ & 3768,39 & - & 1434,11 & 965,94 & 1466,4 & 6200,73 \\
\hline
\end{tabular}

TABLE 8: Results when all transports are conducted through route B.

\begin{tabular}{|c|c|c|c|c|c|c|}
\hline \multicolumn{6}{|c|}{ Average results from 2nd Scenario after simulation replications } & \multirow{2}{*}{$\begin{array}{l}\text { Sum of Average } \\
\text { Costs after } \\
\text { simulation } \\
\text { replications }\end{array}$} \\
\hline & $\begin{array}{l}\text { Total time in which } \\
\text { the products were } \\
\text { in transit }(\mathrm{h})\end{array}$ & $\begin{array}{l}\text { Number of vehicles } \\
\text { in use after } 9 \text { p.m. }\end{array}$ & $\begin{array}{l}\text { Total travel time } \\
\text { after } 9 \text { p.m. }\end{array}$ & $\begin{array}{l}\text { Total time in which } \\
\text { the products were } \\
\text { found stored }(\mathrm{h})\end{array}$ & $\begin{array}{c}\text { Amount of } \\
\text { products that were } \\
\text { not transported }\end{array}$ & \\
\hline $\begin{array}{l}\text { Average results } \\
\text { after simulation } \\
\text { replications }\end{array}$ & 306,12 & 17 & 66,38 & 502,07 & 2,84 & - \\
\hline $\begin{array}{l}\text { Average costs after } \\
\text { simulation } \\
\text { replications }\end{array}$ & 3775,8 & - & 1078,7 & 941,38 & 710,2 & 5427,38 \\
\hline
\end{tabular}

TABLE 9: Results when the decision making process uses the proposed control.

\begin{tabular}{|c|c|c|c|c|c|c|}
\hline \multicolumn{6}{|c|}{ Average results from 3rd Scenario after simulation replications } & \multirow{2}{*}{$\begin{array}{l}\text { Sum of average } \\
\text { Costs after } \\
\text { simulation } \\
\text { replications }\end{array}$} \\
\hline & $\begin{array}{l}\text { Total time in which } \\
\text { the products were } \\
\text { in transit (h) }\end{array}$ & $\begin{array}{l}\text { Number of vehicles } \\
\text { in use after } 9 \text { p.m. }\end{array}$ & $\begin{array}{l}\text { Total travel time } \\
\text { after } 9 \text { p.m. }\end{array}$ & $\begin{array}{l}\text { Total time in which } \\
\text { the products were } \\
\text { found stored }(\mathrm{h})\end{array}$ & $\begin{array}{l}\text { Amount of } \\
\text { products that were } \\
\text { not transported }\end{array}$ & \\
\hline $\begin{array}{l}\text { Average results } \\
\text { after simulation } \\
\text { replications }\end{array}$ & 249,84 & 12 & 65,89 & 461,44 & 1,32 & - \\
\hline $\begin{array}{l}\text { Average costs after } \\
\text { simulation } \\
\text { replications }\end{array}$ & 3140,15 & - & 1070,64 & 865,19 & 331,05 & 4336,39 \\
\hline
\end{tabular}

out that the difference between the results of the 1st and 2 nd Scenarios is due to the low processing time $\left(T_{P}\right)$ for transport vehicles at the bottleneck of route $B$. Compared to the sum of average costs after simulation replications of the 1st Scenario, the 2nd Scenario presented a lower value.

In the 3rd Scenario, the decision on the route that was used to carry out the shipping of the goods was made with the aid of the proposed control element. In this case, it was observed that all cost factors were lower compared to the other two scenarios. The sum of average costs after simulation replications of this scenario, in comparison to the cost of all other scenarios, presented the lowest value.

\section{Conclusion}

A greater consistency of goods carried was identified when the transport scheduling decision takes into account the expectation about the time calculated by applying queues stochastic models, which would be spent in queues. Furthermore, it was also possible to observe a reduction in storage time and the time of goods in transit after the change in the decision process. The improvement performed at the decision process could be implemented in real-world port logistic systems through the application of a customised version of the proposed model.

Regarding reductions in storage time and the time of goods in transit after the change in the decision process, although this study did not demonstrate these benefits, they are related to the reduction in the level of safety stock held along the port logistic system. Thus, this work demonstrated the possibility of achieving a better performance of a port logistic system without necessarily making a change in its structure or infrastructure, only by improving the synchronization of transport flows through the application of a queueing model for supporting scheduling decision making.

Nevertheless, some limitations have to be pointed out. The model assumes the occurrence of only one queue along the transport route. When there is more than one bottleneck on the same route, the resulting flow of goods is determined 
by the bottleneck with the lowest capacity. During a transport journey, it is possible that the vehicle passes through several traffic congestions. In this case, the elapsed time in the traffic congestion is associated with the service capacity limit of different segments along a route. The control element takes into account an expectation about the time that would be spent in queues. If there is more than one queue on a route, it would be necessary to monitor and inform the size of these queues to the control element.

\section{Conflict of Interests}

The authors declare that there is no conflict of interests regarding the publication of this paper.

\section{Acknowledgments}

This paper was supported by (i) a Grant from Simio LLC covering software licenses; (ii) two Grants from CNPq (the Brazilian National Council for Scientific and Technological Development): a Scientific Initiation Grant (Bolsista de Iniciação Científica-PIBIC) and a Senior Researcher Grant (Bolsista de Produtividade em Pesquisa do CNPq-PQ Nível 2, Processo 303879/2012-2); and (iii) one Master Student Grant from CAPES (Coordenação de Aperfeiçoamento de Pessoal de Nivel Superior). The authors would also like to thank the reviewers for the important comments and suggestions which contributed to the continuous improvement of this research paper.

\section{References}

[1] A. M. Valente, E. Passaglia, J. A. Cruz et al., Qualidade E Produtividade Nos Transportes, Cengage Learning, São Paulo, Brazil, 2008.

[2] M. F. Hijjar and F. M. B. Alexim, "Avaliação do acesso aos terminais portuários e ferroviários de contêineres no Brasil. Coppead/UFRJ, Centro de Estudos em Logística," http://www .coppead.ufrj.br/pt-br/upload/publicacoes/ArtLog_SET_2006 .pdf/.

[3] A. Chin and J. Tongzon, "Maintaining Singapore as a major shipping and air transport hub," in Competitiveness of the Singapore Economy, T. Toh, Ed., pp. 83-114, Singapore University Press, 1998.

[4] R. Bittencourt, Modelo de apoio ao controle de acesso de veículos pelo modal rodoviário junto aos portos utilizando tecnologia RFID. [Dissertação Mestrado em Engenharia Civil], Universidade Federal de Santa Catarina, Florianópolis, Brazil, 2012.

[5] O. Sharif, N. Huynh, and J. M. Vidal, "Application of El Farol model for managing marine terminal gate congestion," Research in Transportation Economics, vol. 32, no. 1, pp. 81-89, 2011.

[6] G. Chen, K. Govindan, and Z. Yang, "Managing truck arrivals with time windows to alleviate gate congestion at container terminals," International Journal of Production Economics, vol. 141, no. 1, pp. 179-188, 2013.

[7] B. Yang and N. Burns, "Implications of postponement for the supply chain," International Journal of Production Research, vol. 41, no. 9, pp. 2075-2090, 2003.

[8] B. Scholz-Reiter, E. M. Frazzon, and T. Makuschewitz, "Integrating manufacturing and logistic systems along global supply chains," CIRP Journal of Manufacturing Science and Technology, vol. 2, no. 3, pp. 216-223, 2010.

[9] E. M. Frazzon, S. Loureiro, J. R. Orlando Fontes Lima, and B. Scholz-Reiter, "A knowledge management approach for the integration of manufacturing and logistics in global production networks," in Proceedings of the 44th CIRP Conference on Manufacturing Systems, Madison, Wis, USA, June 2011.

[10] A. Scholl, Robuste Planung und Optimierung: Grundlagen, Konzepte und Methoden; Experimentelle Untersuchungen, Physica, Heidelberg, Germany, 2001.

[11] J. Mula, D. Peidro, M. Díaz-Madroñero, and E. Vicens, "Mathematical programming models for supply chain production and transport planning," European Journal of Operational Research, vol. 204, no. 3, pp. 377-390, 2010.

[12] D. Huisman, R. Freling, and A. P. M. Wagelmans, "A robust solution approach to the dynamic vehicle scheduling problem," Transportation Science, vol. 38, no. 4, pp. 447-458, 2004.

[13] W. Herroelen and R. Leus, "Project scheduling under uncertainty: survey and research potentials," European Journal of Operational Research, vol. 165, no. 2, pp. 289-306, 2005.

[14] A. A. Assad, "Models for rail transportation," Transportation Research A: General, vol. 14, no. 3, pp. 205-220, 1980.

[15] S. Raff, "Routing and scheduling of vehicles and crews. The state of the art," Computers and Operations Research, vol. 10, no. 2, pp. 63-211, 1983.

[16] C. B. Cunha, Uma contribuição para o problema de roteirização de veículos com restrições operacionais, EPUSP, Departamento de Engenharia de Transporte, São Paulo, Brazil, 1997.

[17] U. O. Bonasser and N. D. F. Gualda, "Um problema de roteirização nas operações de transporte da força aérea brasileira," in Proceedings of the 18th ANPET Congresso Nacional de Pesquisa e Ensino em Transporte, Florianópolis, Brazil, November 2004.

[18] H. T. Papadopoulos and C. Heavey, "Queueing theory in manufacturing systems analysis and design: a classification of models for production and transfer lines," European Journal of Operational Research, vol. 92, no. 1, pp. 1-27, 1996.

[19] Y. H. Abdelkader and M. Al-Wohaibi, "Computing the performance measures in queueing models via the method of order statistics," Journal of Applied Mathematics, vol. 2011, Article ID 790253, 12 pages, 2011.

[20] B. Dragović, N. Park, N. Zrnić, and R. Meštrović, "Mathematical models of multiserver queuing system for dynamic performance evaluation in port," Mathematical Problems in Engineering, vol. 2012, Article ID 710834, 19 pages, 2012.

[21] H. Wu and T. Chen, "A fuzzy-neural ensemble and geometric rule fusion approach for scheduling a wafer fabrication factory," Mathematical Problems in Engineering, vol. 2013, Article ID 956978, 14 pages, 2013.

[22] H. Tsai and T. Chen, "A fuzzy nonlinear programming approach for optimizing the performance of a four-objective fluctuation smoothing rule in a wafer fabrication factory," Journal of Applied Mathematics, vol. 2013, Article ID 720607, 15 pages, 2013.

[23] S. S. Panwalkar and W. Iskander, "A survey of scheduling rules," Operations Research, vol. 25, no. 1, pp. 1-18, 1977.

[24] P. Azimi, H. Haleh, and M. Alidoost, "The selection of the best control rule for a multiple-load AGV system using simulation and fuzzy MADM in a flexible manufacturing system," Modelling and Simulation in Engineering, vol. 2010, Article ID 821701, 11 pages, 2010. 
[25] D. J. Bowersox and D. J. Closs, "A simulation in logistics: a review of present practice and a look to the future," Journal of Business Logistics, vol. 10, no. 1, pp. 133-148, 1989.

[26] A. Micu, A. E. Micu, V. Mazilescu, and C. Nistor, "Simulation in logistics network context: theoretical approach of the optimization process," Universitatea Petrol-Gaze Ploiesti, vol. 60, pp. 95-104, 2008.

[27] J. M. Swaminathan, S. F. Smith, and N. M. Sadeh, "Modeling supply chain dynamics: a multiagent approach," Decision Sciences, vol. 29, no. 3, pp. 607-631, 1998.

[28] SIMIO LLC, Sewickley, Pa, USA, 2014; http://www.simio.com/. 


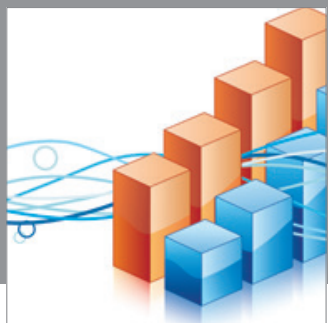

Advances in

Operations Research

mansans

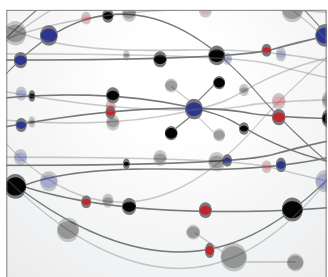

The Scientific World Journal
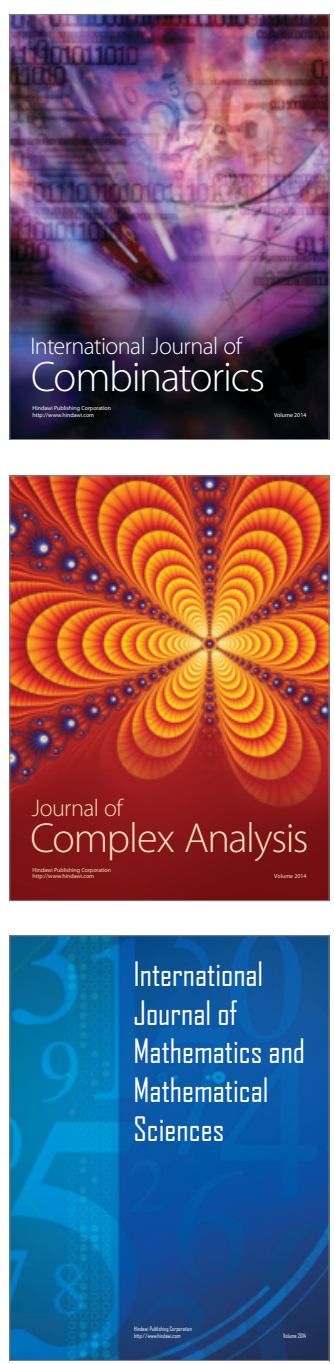
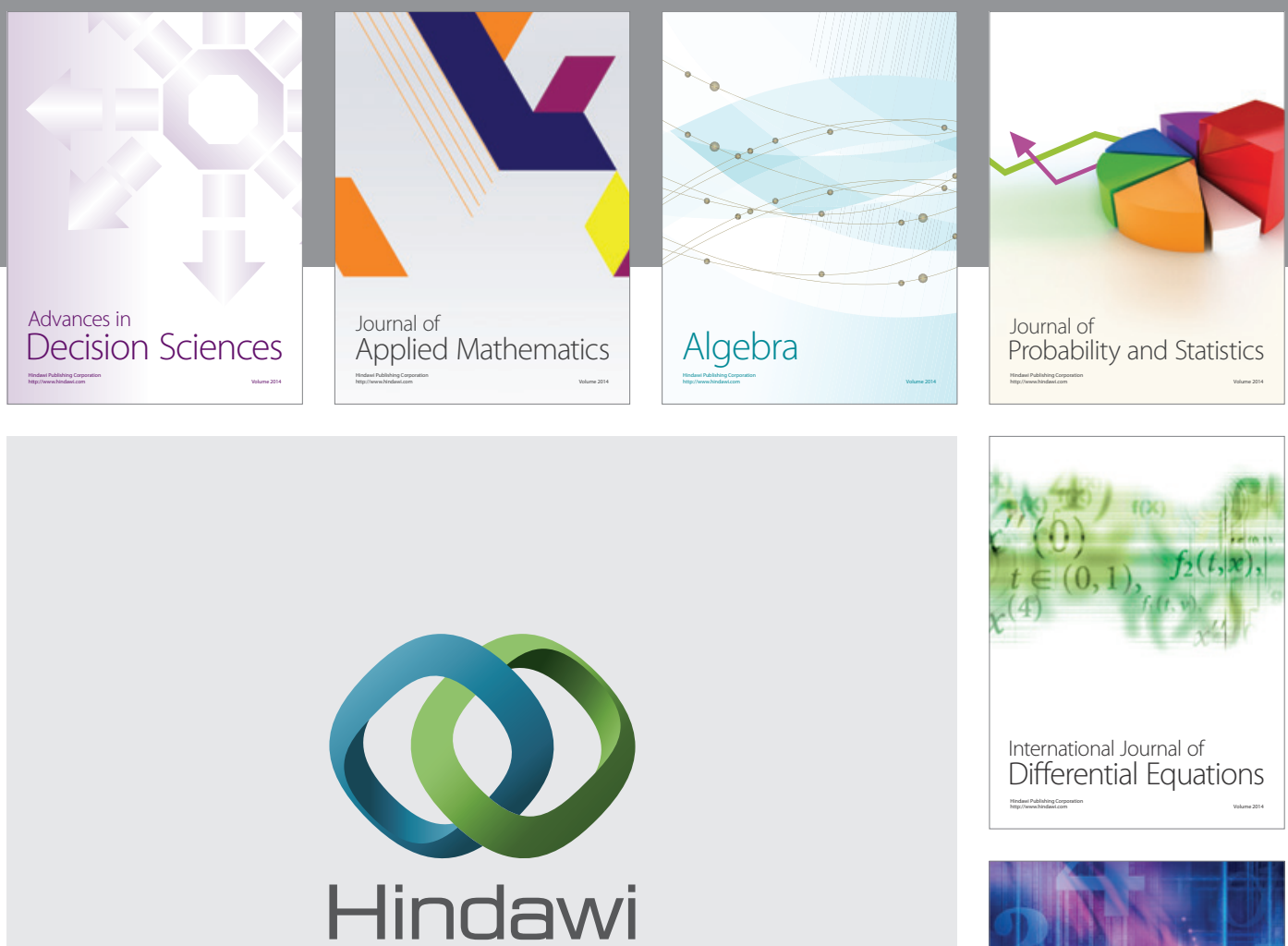

Submit your manuscripts at http://www.hindawi.com
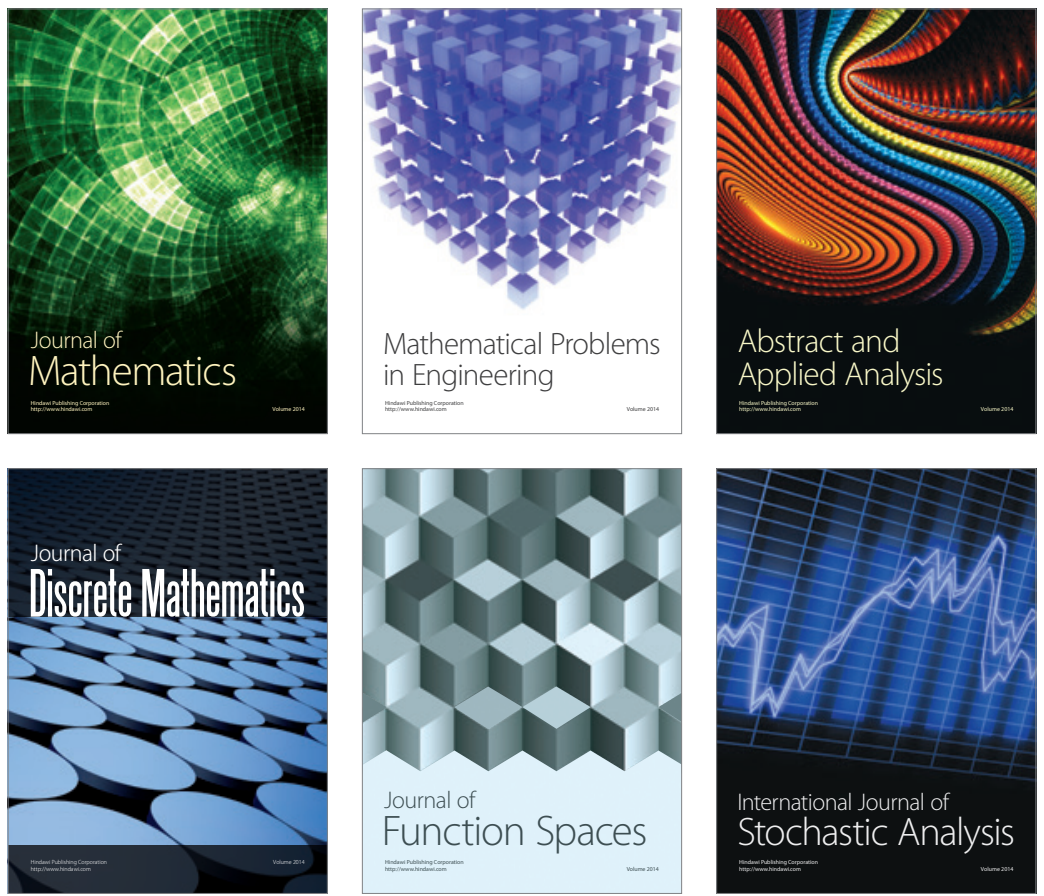

Journal of

Function Spaces

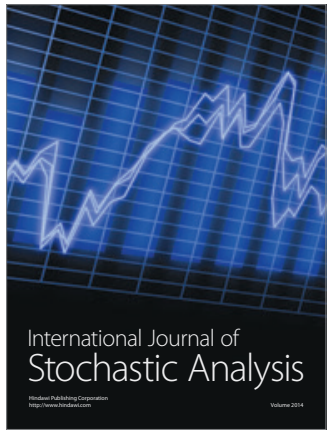

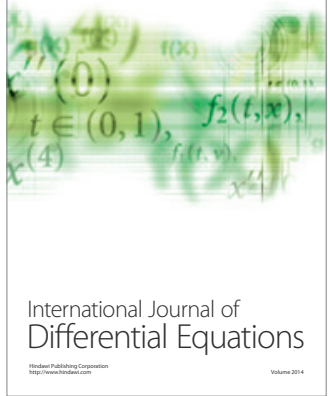
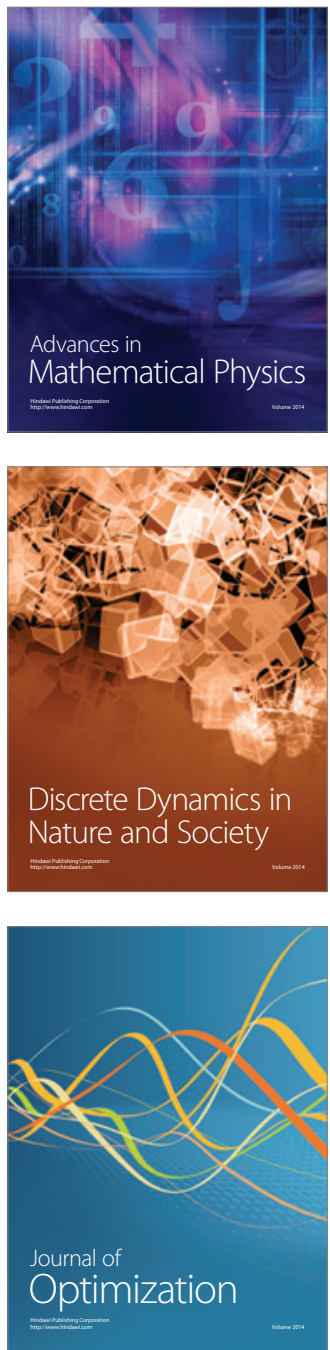